\title{
TINGKAT PENGETAHUAN MAHASISWA PROGRAM STUDI PENDIDIKAN GEOGRAFI JURUSAN GEOGRAGI FIS UNP TAHUN MASUK 2013 - 2016 TENTANG KARTOGRAFI
}

\author{
Muhamad Rais \\ Program Studi Pendidikan Geografi, \\ Fakultas Ilmu Sosial, Universitas Negeri Padang \\ Email: ajomuhamadrais@gmail.com
}

\begin{abstract}
Abstrak
Penelitian ini bertujuan untuk mengungkapdata tentang Tingkat Pengetahuan mahasiwa Program Studi Pendidikan Geografi Jurusan Geografi FIS UNP Tahun Masuk 2013-2016 tentang kartografi.Penelitian ini tergolong penelitian diskriptif dengan pendekatan Kuantitatif Method. Dalam penelitian ini penarikan sampel dilakukan dengan teknik Simple Random Sampling sehingga sampel berjumlah 85 mahasiswa. Teknik analisa data yang digunakan dalam penelitian ini yaitu diskriptif dengan persentase. Hasil penelitian menunjukkan bahwa :(1) Tingkat pengetahuan mahasiswa Program Studi Pendidikan Geografi FIS UNP tahun masuk 2013-2016 tentang kartografi yang masuk dalam kategori cukup tinggi pada materi konsep dan hafalan dan rendah pada materi hitung-hitungan.
\end{abstract}

Kata Kunci: Tingkat Pengetahuan, Mahasiswa, Kartografi.

\begin{abstract}
This study aims to reveal data about the knowledge level of students in Geography Education Program at FIS UNP 2013-2016 Academic Year. This research is a descriptive research with Kuantitatif Method approach. In this research the sampling is Simple Random Sampling technique with the sample is 85 students. The data analysis technique used in this research is descriptive with percentage. The results showed that: The knowledge level of students in GeographyEducation Program at FIS UNP 2013-2016 Academic Year about cartographywhich included into high enoughcategory on concept and rote materialand low oncalculation.
\end{abstract}

Keywords: Knowledge Level, Student, Cartography. 


\section{PENDAHULUAN}

Geografi adalah ilmu yang mempelajari hubungan kausal gejalagejala di muka bumi dan peristiwaperistiwa yang terjadi di muka bumi baik yang fisikalmaupun yang menyangkut mahkluk hidup beserta permasalahannya,melaluipendekatan keruangan,ekologikal dan regional untuk kepentingan program, proses dan keberhasilan pembangunan.Geografi juga dapat diartikan sebagai ilmu yang mempelajari segala fenomena yang terjadi di bumi yang sangat berpengaruh bagi kelangsungan hidup manusia. Sepanjang mata memandang dan apa yang kita lihat maupun kita rasakan seperti tanah, air, udara, hewan dan tumbuhan di bumi ini dipelajari dalam geografi.

Berdasarkan bidang kajiannya geografi dibagi menjadi tiga bidang ilmu yakni: a) geografi fisik yang mempelajari bentang lahan (landscape), yaitu bagian ruang di permukaan bumi yang dibentuk oleh adanya depedensi bentuk. b) Geografi manusia mempelajari manusia dalam ruang termasuk di dalamnya jumlah penduduk, penyebaran penduduk, dinamika penduduk, aktivitas ekonomi, politik, sosial, dan budayanya. c) Geografi Teknik mempelajari cara-cara memvisualisasikan dan menganalisis data dan informasi geografis dalam bentuk peta, diagram, foto udara, dan citra hasil penginderaan jauh.

Salah satu cabang ilmu dari geografi teknik adalah kartografi. Menurut Aryono Prihandito (1984) Kartografi adalah ilmu yang mempelajari peta, dimulai pengumpulan data di lapangan, pengolahan data, simbolisasi, penggambaran, analisas peta, serta interpretasi peta. Dapat dikatakan bahwa, kartografi merupakan ilmu, seni, dan teknik membuat peta.

Selain itu Nursyid (1988:63) mengatakan bahwa salah satu kemampuan khusus pada studi geografi yakni mampu menggunakan dan membuat peta, mengetahui bermacam-macam peta berdasarkan jenis, skala dan penggunaanya. Kartografi adalah mata kuliah yang mempelajari pengertian kartografi, peta, atlas dan mental map, sejarah kartografi, fungsi peta, persyaratan peta, unsur-unsurpeta kontur, simbol peta, skala, proyeksi peta, namanama geografi, sumber data dan membaca peta. Setelah mengikuti perkuliahan kartografi mahasiswa diharapkan memiliki wawasan dan keterampilan tentang peta, meliputi cara membaca peta, membuat peta, interpretasi peta sebagai alat untuk analisis fenomena/gejala geosfer, sehingga sangat penting peran dan fungsinya untuk mempelajari permukaan bumi.

Hal ini dipelajari dalam ilmu kartografi, dalam (Setyowati 2014) ada beberapa materi yang terdapat pada dasar kartografi seperti : (1) Peta, Atlas, Globe, (2). Komponen Peta (3) Tata letak Peta (4) Letering (5) Skala Peta (6) Proyeksi Peta (7) Simbol Peta (8)Penggambaran Relief (9) Membaca dan menginterpretasi citra (10) Membuat peta sederhana.

Setelah mengikuti perkuliahan kartografi mahasiswa diharapkan memiliki wawasan dan keterampilan tentang peta, meliputi cara membaca peta, membuat peta, interpretasi peta sebagai alat untuk analisis fenomena/gejala geosfer, sehingga sangat penting peran dan fungsinya 
untuk mempelajari permukaan bumi. Mata kuliah kartografi juga menjadi prasyarat wajib bagi mata kuliah lanjutan di jurusan geografi seperti, pratikum kartografi, penginderaan jauh, dan sistem informasi geografis. Semua penelitian dan analisis dalam geografi pasti menggunakan peta baik sebagai alat bantu maupun hasil. Untuk itu, pemahaman dan penguasaan mata kuliah kartografi sangat penting dan mendasar bagi mahasiswa geografi. Semestinya mahasiswa yang telah lulus mata kuliah kartografi mempunyai pengetahuan yang lebih baik tentang kartografi.

Berdasarkan observasi dan wawancara awal penulis dengan beberapa mahasiswa. Masih banyak mahasiswa Program Studi Pendidikan Geografi merasa kesulitan dalam mengikuti proses perkuliahan dalam mata kuliah lanjutankartografi seperti Penginderaan Jauh, Sistem Informasi Geografi, dan Aplikasi Sistem Informasi Geografi. Dalam (Rosanita 2017:6) Hal ini dibuktikan dari nilai salah satu mata kuliah lanjutankartografi yakni Sistem Informasi Geografi yang tergolong rendah pada angkatan 2013 dimana lebih dari 50\% mahasiswa Geografi FIS UNP mendapatkan nilai yang cukup rendah. Faktanya banyak mahasiswa Program Studi Pendidikan Geografi yang tidak memahami cara mencari koordinat suatu titik pada peta, memproyeksikan peta, serta membuat peta langsung dengan menggunakan kaidah-kaidah dalam kartografi dan masih banyak mahasiswa tidak bisa membuat peta menggunakan Arc GIS. Hal serupa juga di sampaikan oleh dosen pembina mata kuliah kartografi ibu Dr. Ernawati, M.Si, dimana dalam pengerjaan tugas - tugas masih banyak yang terlambat mengumpulkan, dan berkerja dengan tidak rapi.

Berdasarkan permasalahan diatas, peneliti tertarik untuk melakukan suatu penelitian yang berjudul "Tingkat Pengetahuan Mahasiswa Program Studi Pendidikan Geografi Jurusan Geografi FIS UNP Tahun Masuk 2013-2016 Tentang Kartografi”.

\section{METODE PENELITIAN}

Penelitian ini merupakan penelitian diskriptif dengan pendekatan kuantitatif, yaitu bertujuan untuk mendeskripsikan atau menjelaskan peristiwa atau suatu kejadian yang terjadi pada saat sekarang dalam bentuk angka-angka yang bermakna, yaitu tingkat pengetahuan mahasiswa program studi Pendidikan Geografi Universitas Negeri Padang Angkatan 2013, 2014, 2015 dan Angkatan 2016. Menurut Suharsimi Arikunto (2010: 3) Penelitian diskriptif adalah penelitian yang benar-benar hanya memaparkan apa yang terdapat atau terjadi dalam sebuah kancah, lapangan, atau wilayah tertentu (objek). Metode penelitian yang digunakan adalah tes dengan menggunakan instrumen berupa tes pilihan ganda dan wawancara terbuka sebagai alat pengumpul data.

Variabel dalam penelitian ini adalah variabel tunggal, yaitu tingkat pengetahuan mahasiswa Angkatan 2013, 2014, 2015 dan Angkatan 2016 tentang kartografi di Program 
Studi Pendidikan Geografi Jurusan Geografi FIS UNP.

Dalam penelitian ini penarikan sampel dilakukan dengan teknik Simple Random Sampling sehingga sampel berjumlah 85 mahasiswa.Penelitian ini dilakukan di Jurusan Geografi Fakultas Ilmu Sosial Universitas Negeri Padang, dengan subjek penelitian adalah mahasiswa Program Studi Pendidikan Geografi tahun masuk 2013-2016 penelitian ini dilaksanakan pada bulan oktober 2017. Instrumen penelitian adalah suatu alat yang digunakan untuk mengukur fenomena alam dan sosial yang terjadi. Dalam hal ini fenomena tersebut adalah variabel penelitian. Data dalam penelitian ini diperoleh dari tes yang diberikan kepada kelompok sampel untuk memperoleh data tentang tingkat pengetahuan mahasiswa. Untuk mendapatkan hasil yang baik dilakukan langkahlangkah sebagai berikut: membuat kisi-kisi tes, menyusun tes, uji coba tes dan serta melakukan analisis soal tes.Sebelum tes diberikan kepada kelas sampel terlebih dahulu dilakukan uji coba untuk mengetahui validitas, reliabilitas, taraf kesukaran dan daya beda yang akan diuji. Berikut dibahas mengenai validitas, reliabilitas, taraf kesukaran dan daya beda:

1. Validitas

Suatu soal dikatakan valid apabila soal itu dapat mengukur apa yang hendak diukur. Soal tes yang disusun disesuaikan dengan silabus mata kuliah kartografi. Validitas yang dilakukan dalam penelitian ini adalah validitas konstruk (contruct validity) dan validitas isi.

\section{Tingkat kesukaran}

Soal-soal yang terlalu mudah dan terlalu sulit tidak baik digunakan sebagai alat ukur. Oleh karena itu perlu mengetahui tingkat kesukaran soal-soal tersebut guna diadakan revisi. Untuk menentukan tingkat kesukaran soal digunakan persamaan:

$$
P=\frac{B}{J S}
$$

Keterangan:

$\mathrm{P}=$ Tingkat kesukaran

$\mathrm{B}=$ Jumlah siswa yang menjawab soal dengan benar

Js = Jumlah seluruh siswa yang mengikuti ujian

Tingkat kesukaran soal dapat diklasifikasikan seperti tabel berikut:

Tabel 4. Klasifikasi tingkat kesukaran soal

\begin{tabular}{|c|c|c|}
\hline No & Index Kesukaran & Klasifikasi \\
\hline 1 & $0,00 \leq \mathrm{P} \leq 0,30$ & Sukar \\
\hline 2 & $0,30 \leq \mathrm{P} \leq 0,70$ & Cukup \\
\hline 3 & $\mathrm{P} \geq 0,70$ & Mudah \\
\hline
\end{tabular}

3. Indek Daya Pembeda

Daya pembeda soal merupakan suatu indikator untuk membedakan antara mahasiswa yang tahu dan mahasiswa yang kurang tahu.

Rumus untuk menghitung daya pembeda adalah :

$D=P A-P B$
$P A=\frac{B A}{J A}$
$P B=\frac{B B}{J B}$

Keterangan:

PA $=$ Proporsi testee kelompok atas yang dapat menjawab dengan betul butir item yang bersangkutan $\mathrm{PB}=$ Proporsi testee kelompok bawah yang dapat menjawab dengan betul butir item yang bersangkutan 
$\mathrm{JA}=$ Banyaknya peserta kelompok atas

$\mathrm{JB}=$ Banyaknya peserta kelompok bawah

$\mathrm{BA}=$ Banyaknya peserta kelompok atas yang menjawab benar

$\mathrm{BB}=$ Banyaknya peserta kelompok bawah yang menjawab benar

Tabel 5. Klasifikasi Daya Pembeda Soal

\begin{tabular}{|c|c|c|}
\hline No & $\begin{array}{c}\text { Indeks daya } \\
\text { pembeda }\end{array}$ & Klasifikasi \\
\hline 1 & $0,00 \leq \mathrm{D}<0,20$ & Jelek \\
\hline 2 & $0,20 \leq \mathrm{D}<0,40$ & Sedang \\
\hline 3 & $0,40 \leq \mathrm{D}<0,70$ & Baik \\
\hline 4 & $0,70 \leq \mathrm{D}<1,00$ & $\begin{array}{c}\text { Baik } \\
\text { Sekali }\end{array}$ \\
\hline
\end{tabular}

4. Reliabilitas

Agar suatu instrumen dapat dipercaya sebagai alat pengumpul data, maka perlu digunakan uji reliabilitas (keandalan). Menurut Sutrisno Hadi (1991: 3), syarat keandalan suatu instrumen menuntut kemantapan, keajegan, atau stabilitas hasil pengamatan dengan instrumen (pengukuran), seandainya barang atau orang yang diamati dalam keadaan tidak berubah dalam kurun waktu amatan pertama, kedua atau amatan-amatan selanjutnya.

Teknik yang dipakai untuk menentukan reliabilitas adalah dengan rumus Alpha:

$$
r 11=\left(\frac{k}{k-1}\right)\left(1-\frac{\sum \sigma b^{2}}{\sigma t^{2}}\right)
$$

AnalisisTingkat Pengetahuan Mahasiswa Program Studi Pendidikan GeografiTahun 20132016 FIS UNP TentangKartografi dianalisis dengan bantuan komputer progam SPSS 16.0 for windows. Dari hasil analisis menghasilkan $\mathrm{rtt}=$ $0,610>$ rtabel $=0,217$.

Data yang dikumpulkan dalam penelitian ini berupa data tingkat pengetahuan mahasiswa geografi program studi pendidikan geografi tentang dasar - dasar kartografi. Untuk mengumpulkan data tersebut digunakan tes pilihan ganda disajikan dengan empat alternative jawaban yaitu a, b, c, dan d. Untuk jawaban yang benar diberikan nilai 1 dan untuk jawaban yang salah diberikan nilai 0. Semakin tinggi bobot skor jawaban yang diperoleh berarti semakin baik tingkat pengetahuan mahasiswa tentang katografi.

Setelah data diperoleh, langkah berikutnya adalah dengan menganalisis data untuk menarik kesimpulan dari penelitian yang dilakukan.Untuk

menganalisisdigunakan statistik, analisis data yang digunakan dari penelitian ini menggunakan teknik analisis data diskriptif dengan persentase. Menurut Anas Sudijono (2011: 42) perhitungan itu menggunakan rumus sebagai berikut

$$
\mathrm{P}=\frac{f}{n} x 100
$$

Keterangan :

$\mathrm{P}:$ persentase

$f$ : frekuensi

$n$ : jumlah subyek

Sumber: (Sudijono 2011:42)

Selanjutnya data-data penelitian yang diperoleh tersebut diintepretasikan dalam kalimat kualitatif (pengetahuan tinggi, pengetahuan cukup tinggi, pengetahuan rendah, pengetahuan sangat rendah). Penilaiannya menggunakan skala empat, dengan kriteria dari Suharsimi Arikunto (1993: 196). Berikut pengkategorian pengetahuan mahasiswa Program Studi Pendidikan Geografi, Jurusan 
Geografi terhadap dasar - dasar kartografi sebagai berikut:

\begin{tabular}{|c|c|c|}
\hline No & $\begin{array}{c}\text { Kategori Tingkat } \\
\text { Pengetahuan }\end{array}$ & $\begin{array}{c}\text { Persentase } \\
\text { Nilai Benar }\end{array}$ \\
\hline 1 & Tinggi & $76 \%-100 \%$ \\
\hline 2 & Cukup Tinggi & $56 \%-75 \%$ \\
\hline 3 & Rendah & $40 \%-55 \%$ \\
\hline 4 & Sangat Rendah & $<40 \%$ \\
\hline
\end{tabular}

\section{HASIL DAN PEMBAHASAN}

Hasil penelitian ini terdiri dari dua bagian. Pertama, Tingkat pengetahuan mahasiswa Program Studi Pendidikan Geografi Jurusan Geografi FIS UNP Tahun masuk 2013-2016 tentang kartografi. Kedua, faktor penyebab dari hasil penelitian tingkat pengetahuan mahasiswa Program Studi Pendidikan Geografi Jurusan Geografi FIS UNP Tahun 20132016 tentang kartografi.

1. Tingkat pengetahuan mahasiswa Program Studi Pendidikan Geografi Jurusan Geografi FIS UNP Tahun masuk 2013-2016 tentang kartografi

Tingkatpengetahuan

mahasiswa Program Studi Pendidikan Geografi Jurusan Geografi FIS UNP tahun masuk 2013-2016 diukur dengan menggunakan tes pilihan ganda yang berjumlah 30 butir pertanyaan dengan skor 1 jika benar dan 0 jika salah. Setelah data ditabulasi, diskor, dan dianalisis dengan menggunakan Microsoft Excel 2007 For Windows, diperoleh hasil dengan rata-rata sebesar 51,6. deskripsi hasil penelitian tingkat pengetahuan mahasiswa Program Studi Pendidikan Geografi Jurusan Geografi FIS UNP dapat dilihat pada tabel dibawah ini.

\begin{tabular}{|c|c|c|c|}
\hline Kategori & Interval & Frekuensi & $\begin{array}{c}\text { Persen } \\
(\%)\end{array}$ \\
\hline Tinggi & $\begin{array}{c}76 \%- \\
100 \%\end{array}$ & 8 & 9,4 \\
\hline $\begin{array}{c}\text { Cukup } \\
\text { Tinggi }\end{array}$ & $\begin{array}{c}56 \%- \\
75 \%\end{array}$ & 41 & 48,2 \\
\hline Rendah & $\begin{array}{c}40 \%- \\
55 \%\end{array}$ & 20 & 23,5 \\
\hline $\begin{array}{c}\text { Sangat } \\
\text { Rendah }\end{array}$ & $<40 \%$ & 16 & 18,8 \\
\hline \multicolumn{2}{|c|}{ Jumlah } & 85 & 100,0 \\
\hline
\end{tabular}

Berdasarkan tabeldiatas dapat diketahui tingkatpengetahuan mahasiswa Program Studi Pendidikan Geografi Jurusan Geografi FIS UNP angkatan 20132016 tentang dasar kartografi yaitu 16 orang $(18,8 \%)$ mempunyai pengetahuan sangat rendah, 20 orang $(23,5 \%)$ mempunyai pengetahuan rendah, 41 orang $(48,2 \%)$ mempunyai pengetahuan cukup tinggi, 8 orang $(9,4 \%)$ mempunyai pengetahuan tinggi. Dengan rata rata nilai 51,6\% yang masuk dalam kategori rendah. Dengan demikian tingkat pengetahuan mahasiswa Program Studi Pendidikan Geografi Jurusan Geografi FIS UNP angkatan 2013-2016 tentang dasar kartografi adalah rendah.

2. Faktor Penyebab Dari Hasil Penelitian Tingkat Pengetahuan Mahasiswa Jurusan Geografi Program Studi Pendidikan Geografi Tahun 2013-2016 FIS UNP Tentang Kartografi

Pada indikator satu yakni mengenai tingkat pengetahuan mahasiswa Program Studi Pendidikan Geografi Jurusan Geografi FIS UNP angkatan 2013- 
2016 tentang skala, simbol, dan komponen peta pada peta dengan nilai rata - rata $57,1 \%$ yang masuk dalam kategori cukup tinggi hal ini dikarenakan materi ini merupakan pengetahuan dasar yang harus dipahami, dengan materi yang dianggap sulit yakni pada materi skala peta, dikarenakan masih kurang memahami tentang skala peta. Deskripsi hasil penelitian tingkat pengetahuan mahasiswa Program Studi Pendidikan Geografi Jurusan Geografi FIS UNP untuk indikator pertama dapat dilihat pada tabel dibawah ini.

\begin{tabular}{|c|c|c|c|}
\hline Kategori & Interval & Frekuensi & $\begin{array}{c}\text { Persen } \\
(\%)\end{array}$ \\
\hline TINGGI & $\begin{array}{c}76 \%- \\
100 \%\end{array}$ & 17 & 20,0 \\
\hline $\begin{array}{c}\text { CUKUP } \\
\text { TINGGI }\end{array}$ & $\begin{array}{c}56 \%- \\
75 \%\end{array}$ & 37 & 43,5 \\
\hline RENDAH & $\begin{array}{c}40 \%- \\
55 \%\end{array}$ & 12 & 14,1 \\
\hline $\begin{array}{c}\text { SANGAT } \\
\text { RENDAH }\end{array}$ & $40 \%$ & 19 & 22,4 \\
\hline \multicolumn{2}{|c|}{ JUMLAH } & 85 & 100,0 \\
\hline
\end{tabular}

Pada indikator dua yakni mengenai tingkat pengetahuan mahasiswa Program Studi Pendidikan Geografi Jurusan Geografi FIS UNP angkatan 20162013 tentang skala, simbol, dan komponen peta pada peta dengan nilai rata - rata 43,5 yang masuk dalam kategori rendah. hal ini dikarenakan materi ini merupakan materi yang cukup sulit, dengan materi yang dianggap sulit yakni pada materi generalisasi peta, proyeksi peta, dan kemiringan lereng dikarenakan pada materi ini masih kurang dipahami karna membutuhkan kemampuan analisis yang cukup tinggi. Deskripsi hasil penelitian tingkat pengetahuan mahasiswa Program Studi
Pendidikan Geografi Jurusan Geografi FIS UNP untuk indikator pertama dapat dilihat pada tabel dibawah ini.

\begin{tabular}{|c|c|c|c|}
\hline Kategori & Interval & Frekuensi & $\begin{array}{c}\text { Persen } \\
(\%)\end{array}$ \\
\hline Tinggi & $\begin{array}{c}76 \%- \\
100 \%\end{array}$ & 1 & 1,2 \\
\hline $\begin{array}{c}\text { Cukup } \\
\text { Tinggi }\end{array}$ & $\begin{array}{c}56 \%- \\
75 \%\end{array}$ & 34 & 40,0 \\
\hline Rendah & $\begin{array}{c}40 \%- \\
55 \%\end{array}$ & 27 & 31,8 \\
\hline $\begin{array}{c}\text { Sangat } \\
\text { Rendah }\end{array}$ & $<40 \%$ & 23 & 27,1 \\
\hline \multicolumn{2}{|c|}{ Jumlah } & 85 & 100,0 \\
\hline
\end{tabular}

Pertama, Tingkat pengetahuan mahasiswa Program Studi Pendidikan Geografi Jurusan Geografi FIS UNP Tahun 20132016 tentang kartografi yaitu 16 orang $(18,8 \%) \quad$ mempunyai pengetahuan sangat rendah, 20 orang $(23,5 \%)$ mempunyai pengetahuan rendah, 41 orang $(48,2 \%)$ mempunyai pengetahuan cukup tinggi, 8 orang $(9,4 \%)$ mempunyai pengetahuan tinggi. Dengan rata rata nilai 51,6\% yang masuk dalam kategori rendah. Dengan demikian tingkat pengetahuan mahasiswa Program Studi Pendidikan Geografi Jurusan Geografi FIS UNP Tahun 2013-2016 tentang kartografi adalah rendah.

Dalam Nursyid (1988:63) mengatakan bahwa salah satu kemampuan khusus pada studi geografi yakni mampu menggunakan dan membuat peta, mengetahui bermacam-macam peta berdasarkan jenis, skala dan penggunaanya. Hal ini di pelajari dalam ilmu kartografi, dalam (setyowati 2014) ada beberapa hal materi yang terdapat pada dasar kartografi seperti: (1) Peta, Atlas, Globe, (2). Komponen Peta (3) Tata letak Peta (4) Letering (5) Skala Peta 
(6) Proyeksi Peta (7) Simbol Peta (8) Penggambaran Relief (9) Membaca dan menginterpretasi citra, (10) Membuat peta sederhana. Dalam hal ini seharusnya mahasiswa Program Studi Pendidikan Geografi, maupun yang kependidikan mampu menguasai materi kartografi dengan baik, agar salah satu kemampuan khusus studi geografi yakni mampu menggunakan dan membuat peta, mengetahui bermacam-macam peta berdasarkan jenis, skala dan penggunaanya bisa terkuasai.

Kedua, faktor penyebab dari hasil penelitian tingkat pengetahuan mahasiswa Program Studi Pendidikan Geografi Jurusan Geografi FIS UNP Tahun 20132016 tentang kartografi yang paling dominan adalah tidak mengusai materi dengan baik. Hal ini didapat setelah melakukan wawancara dengan beberapa mahasiswa Pendidikan geografi tahun 2013 2016, dimana dapat disimpul kan pada dua indikator materi yang diberikan tentang skala, simbol, komponen peta, proyeksi, generalisasi, kemiringan lereng, dan menghitung luas pada peta dengan materi yang dianggap sulit yakni pada materi skala peta, generalisasi peta, proyeksi peta, dan kemiringan lereng dikarenakan pada materi ini masih kurang dipahami karna membutuhkan kemampuan analisis yang cukup tinggi.

Pada indikator pertama yang berisi materi tentang skala, simbol, dan komponen peta. tingkat pengetahuan mahasiswa Program Studi Pendidikan Geografi Jurusan Geografi FIS UNP tahun masuk 2013 - 2016 mendapatkan rata - rata $57,1 \%$ yang masuk dalam kategori cukup tinggi dengan 54 orang $(63,50 \%)$ mahasiswa yang masuk dalam ketegori cukup tinggi dan tinggi. Hal ini dikarenakan mahasiswa Program Studi Pendidikan Geografi Jurusan Geografi FIS UNP tahun masuk 2013 - 2016 telah mengetahui dan memahami materi tentang skala, simbol dan komponen peta yang merupakan materi yang sudah diajarkan dijenjang sekolah menengah, materi yang masih mudah dipahami serta materi dasar yang wajib dipahami oleh mahasiswa Geografi. Namun pada indikator pertama yang berisi materi tentang skala, simbol, dan komponen peta masih ada materi yang dianggap sulit yakni pada materi tentang skala peta. Hal ini dikarenakan materi yang masih dianggap cukup sulit karena membutuhkan ketelitian dan matematika yang baik dalam menghitung, mencari dan merubah skala peta. Serta beberapa mahasiswa Program Studi Pendidikan Geografi telah lupa dan tidak membaca kembali materi - materi yang telah dipelajari setelah lulus pada mata kuliah kartografi.

Pada indikator kedua yang berisi materi tentang proyeksi, generalisasi, kemiringan lereng, mencari titik koordinat pada peta, serta menghitung luas pada peta. Pada indikator ini mahasiswa Program Studi Pendidikan Geografi Jurusan Geografi FIS UNP tahun masuk 2013 - 2016 mencapai nilai rata - rata $43,5 \%$ yang masuk dalam kategori rendah dengan 50 orang $(58,9 \%)$ yang masuk dalam kategori rendah dan sangat rendah. Hal ini dikarenakan mahasiswa Program Studi Pendidikan Geografi FIS UNP 
tahun masuk 2013 - 2016 merasa materi - materi yang ada pada indikator kedua cukup rumit karena pada materi indikator kedua yang banyak menggunakan rumus - rumus dan perhitungan matematik serta ketelitian yang baik. Sehingga masih banyak mahasiswa yang kurang memahami materi - materi yang ada pada indikator kedua ini. Pada indikator kedua hampir semua materi dianggap sulit hal ini disebabkan, mahasiswa merasa masih kurang paham tentang materi tersebut dan saat perkuliahan kartografi kurang mengerti dan butuh penjelasan lebih tentang materi - materi tersebut. Hal ini juga ditambah dengan tidak membaca kembali materi - materi yang telah dipelajari setelah lulus dalam mata kuliah kartografi.

\section{Penutup}

\begin{tabular}{lrr}
\multicolumn{1}{c}{ Tingkat } & \multicolumn{2}{r}{ pengetahuan } \\
mahasiswa & Program & Studi \\
Pendidikan & Geografi & Jurusan
\end{tabular} Geografi FIS UNP angkatan 20132016 tentang kartografi yaitu 16 orang $(18,8 \%) \quad$ mempunyai pengetahuan sangat rendah, 20 orang $(23,5 \%)$ mempunyai pengetahuan rendah, 41 orang $(48,2 \%)$ mempunyai pengetahuan cukup tinggi, 8 orang $(9,4 \%)$ mempunyai pengetahuan tinggi. Dengan rata rata nilai 51,6\% yang masuk dalam kategori rendah. Dengan demikian tingkat pengetahuan mahasiswa Program Studi Pendidikan Geografi Jurusan Geografi FIS UNP angkatan 2013-2016 tentang kartografi adalah rendah.

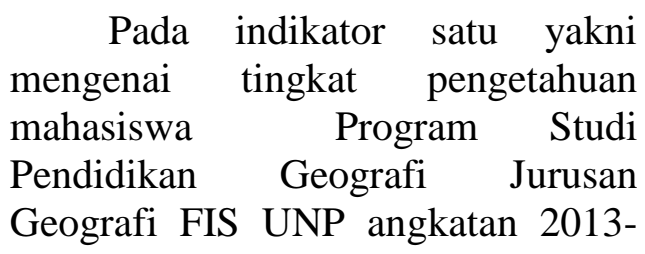

2016 tentang skala, simbol, dan komponen peta pada peta yang masuk dalam kategori cukup tinggi. Hal ini dikarenakan materi ini merupakan pengetahuan dasar yang harus dipahami, dengan materi yang dianggap sulit yakni pada materi skala peta, dikarenakan masih kurang memahami tentang skala peta. pada indikator dua yakni mengenai tingkat pengetahuan mahasiswa Program Studi Pendidikan Geografi Jurusan Geografi FIS UNP angkatan 20132016 tentang proyeksi, generalisasi, kemiringan lereng, dan menghitung luas pada peta yang masuk dalam kategori rendah. Hal ini dikarenakan materi ini merupakan materi yang cukup sulit, dengan materi yang dianggap sulit yakni pada materi generalisasi peta, proyeksi peta, dan kemiringan lereng dikarenakan pada materi ini masih kurang dipahami karna membutuhkan kemampuan analisis yang cukup tinggi.

Saran yang dapat disampaikan setelah mengetahui hasil penelitian antara lain: 1) Untuk Peneliti Selanjutnya, agar mengadakan penelitian tingkat pengetahuan mahasiswa Program studi pendidikan geografi jurusan Geografi FIS UNP angkatan 2013-2016 tentang kartografi dan menghubungkannya dengan variabel lain yang tidak terdapat dalam penelitian ini. 2) Diharapkan bagi mahasiswa Pendidikan geografi agar lebih menguasai materi - materi yang ada dalam mata kuliah kartografi. 


\section{Daftar Pustaka}

Arikunto, Suharsimi.1993. Prosedur Penelitian Pendekatan Praktik. : Jakarta: Rhineka Cipta

Arikunto, Suharsimi. 2010. Prosedur Penelitian. Jakarta: Rineka Cipta.

Hadi, Sutrino. 1991. Analisis Butir

Untuk Instrumen Angket, Tes dan Skala NilaiDengan BASICA. Yogyakarta: Andi Offset.

Notoadmojo, Soekidjo. 2007. Promosi Kesehatan dan Ilmu Perilaku. Jakarta: Rineka citra.

Prihandito, Aryono.1984. Kartografi. Yogyakarta: PT Mitra Gama Widya.

Rosanita, Ratih. 2017. Hubungan Kemampuan Awal Dan Daya Juang Mahasiswa Dengan Hasil Belajar Mahasiswa Geografi 2013 Pada Mata Kuliah Sistem Informasi Geografi Fakultas Ilmu Sosial Universitas Negeri Padang. Skripsi pada UNP.

Sumaatmadja, Nursid. 1998. Studi Geografi.Bandung: PT Alumni.

Sudijono, Anas. 2011. Pengantar Statistik Pendidikan. Rajawali pers

Setyowati, dkk. 2014. Kartografi Dasar. Yogyakarta: Penerbit Ombak 